\title{
ANGPTL4 variants and their haplotypes are associated with serum lipid levels, the risk of coronary artery disease and ischemic stroke and atorvastatin cholesterol- lowering responses
}

\author{
Qian Yang ${ }^{1}$, Rui-Xing Yin ${ }^{1 *}$, Xiao-Li Cao ${ }^{2}$, Feng Huang ${ }^{1}$, Yi-Jiang Zhou ${ }^{1}$ and Wu-Xian Chen ${ }^{1}$
}

\begin{abstract}
Background: This study aimed to assess the association between the angiopoietin-like protein 4 gene (ANGPTL4) single nucleotide polymorphisms (SNPs) and serum lipid levels, the risk of coronary artery disease (CAD) and ischemic stroke (IS), and response to atorvastatin therapy in a Southern Chinese Han population.

Methods: Genotypes of the ANGPTL4 rs4076317, rs7255436, rs1044250 and rs2967605 SNPs in 1,654 unrelated subjects (CAD, 568; IS, 537; and controls, 549) were determined by the Snapshot technology. Another group of 724 hyperlipidemic patients was selected and treated with atorvastatin calcium tablet $20 \mathrm{mg} /$ day for 8 weeks.

Results: The rs2967605 CT/TT genotypes were associated with a decreased risk of CAD (adjusted OR $=0.68,95 \% \mathrm{Cl}$ $=0.47-0.99, P=0.043$ for $C T / T T$ vs. CC) and IS (adjusted $O R=0.55,95 \% \mathrm{Cl}=0.38-0.80, P=0.020$ for $C T / T T$ vs. CC). There was no significant association between the four SNPs and angiographic severity of CAD. The subjects with the rs4076317 CG/CC genotypes in controls had higher total cholesterol (TC) and low-density lipoprotein cholesterol (LDL-C) levels than the subjects with the GG genotype $(P<0.001$; a $P<0.0018$ was regarded statistically significant by the Bonferroni correction). The subjects with rs4076317CG/GG genotypes had lower TC and LDL-C levels than the subjects with CC genotype after atorvastatin treatment $(P<0.001)$.

Conclusions: The observed associations suggest that the ANGPTL4 variants have a potential role on serum lipid levels and atherosclerosis-related diseases in the Chinese Han population, especially the ANGPTL4 rs4076317 and rs2967605 SNPs.
\end{abstract}

Keywords: Angiopoietin-like protein 4 gene, Single nucleotide polymorphism, Coronary artery disease, Ischemic stroke, Lipids, Atorvastatin

\section{Background}

Atherosclerosis development is closely associated with lipid disorders [1-5]. The retention of serum lipoproteins in the artery wall is a key initiator of atherosclerosis [6]. The accumulation of oxidized lipoproteins in the artery wall sets off a cascade of proinflammatory events leading

\footnotetext{
* Correspondence: yinruixing@163.com

'Department of Cardiology, Institute of Cardiovascular Diseases, the First Affiliated Hospital, Guangxi Medical University, Nanning 530021, Guangxi, People's Republic of China

Full list of author information is available at the end of the article
}

to the recruitment of macrophages, lipids uptake into these cells, and the initiation of the chronic inflammatory cascade that characterizes atherosclerosis [6]. Thus, dyslipidemia plays critical roles in the initiation and progression of the atherosclerotic lesion. In recent genome-wide association studies (GWASes), multiple lipid-related loci have been identified, which is important to unravel novel pathways and their relations to atherosclerosis-related diseases, so that provided more effective means of diagnosis, treatment, and prevention for atherosclerosis $[7,8]$.

(c) The Author(s). 2018 Open Access This article is distributed under the terms of the Creative Commons Attribution 4.0 International License (http://creativecommons.org/licenses/by/4.0/), which permits unrestricted use, distribution, and 
Angiopoietin-like protein 4 gene (ANGPTL4) is one of the novel genes associated with serum lipid levels in the Caucasian population $[7,8]$. The human ANGPTL4 is located on chromosome 19p13, which contains seven protein-coding exons and two non-coding exons, and encodes a 406-amino-acid glycoprotein with a molecular mass of $50 \mathrm{kDa}[9,10]$. ANGPTL4 also known as hepatic fibrinogen angiogenic related protein, fasting induced adipose factor, and peroxisome proliferators-activated receptor (PPAR) angiogenic related protein, and these names collectively give insight into the expression and function of the protein $[11,12]$. Previous functional studies revealed that ANGPTL4 regulated plasma triglyceride (TG) levels by inhibiting lipoprotein lipase (LPL) [13-16]. LPL is responsible for catalyzing the hydrolysis of TG in chylomicrons and very low-density lipoproteins (VLDLs) and enhancing the high-density lipoprotein cholesterol (HDL-C) levels, and regulating the supply of fatty acids to various tissues for either storage or oxidation $[17,18]$. ANGPTL4-deficient mice decreased serum TG levels by increasing LPL activity. In contrast, the ANGPTL4 transgenic mice elevated serum TG and reduced LPL activity [14, 15, 19-21].

Some studies have also showed that ANGPTL4 loss-of-function mutations are associated with substantially lower TG levels, and a lower risk of coronary artery disease (CAD) and type 2 diabetes (T2D) [22-25]. Furthermore, ANGPTL4 has been considered to be a promising drug target for therapeutic intervention against hyperlipidemia and atherosclerosis-related diseases. However, there is no universal agreement on the association between the ANGPTL4 variants and serum lipid traits, and the risk of CAD and ischemic stroke (IS) in different populations. Therefore, the purpose of the present study was to assess the association between 4 ANGPTL4 SNPs (rs4076317, rs7255436, rs1044250 and rs2967605) and serum lipid levels, the risk of CAD and IS, and the lipid-lowering efficacy of atorvastatin in a Southern Chinese Han population.

\section{Methods}

\section{Study samples}

The present study enrolled 1,105 unrelated patients with CAD $(n=568)$ and IS $(n=537)$ from hospitalized patients in our First Affiliated Hospital. The diagnosis of CAD was based on typical clinical symptoms and electrocardiographic changes, as well as increases in the serum markers including creatinine kinase-MB and troponin T. Coronary angiography was performed in all CAD patients. Only significant coronary stenosis with lumen narrowing $(\geq 50 \%)$ in at least either one of the three main coronary arteries or their major branches (branch diameter $\geq 2 \mathrm{~mm}$ ) was selected. Additionally, the angiographic severity of disease was defined as single or multi-vessel disease based on the number of involved artery (luminal narrowing $\geq 50 \%$ ) in the three major coronary arteries [26, 27]. All of the IS patients received a strict neurological examination and brain magnetic resonance imaging (MRI). The classification of IS was made according to the Trial of Org 10172 in Acute Stroke Treatment (TOAST) criteria [28]. The selected IS patients included individuals who were eligible for one of the two subtypes of TOAST criteria: Large-artery atherosclerosis and small-vessel occlusion. Subjects with a history of hematologic, neoplastic, renal, liver, thyroid, autoimmune diseases and type I diabetes mellitus were excluded. The CAD patients who had a past history of IS, or the IS cases who had a past history of CAD were excluded from the study. There were 56 patients not included in this study because of the co-existence of both CAD and IS.

In addition, the present study also enrolled 549 control subjects matched by age, gender, and ethnic group (Han Chinese) from Physical Examination Center of our First Affiliated Hospital during the same period. The controls were free of IS and CAD by history taking, clinical, biochemical, and image examinations such as 64-slice computed tomographic coronary angiography. The study design was approved by the Ethics Committee of the First Affiliated Hospital, Guangxi Medical University (No: Lunshen-2011-KY-Guoji-001; Mar. 7, 2011). Informed consent was obtained from all participants.

\section{Atorvastatin treatment group}

Another group of 724 hyperlipidemic patients (controls, 253; CAD, 248 and IS, 223) was also enrolled and treated with atorvastatin calcium tablet (Lipitor, Pfizer Wuxi Pharmaceutical Co., Ltd.) $20 \mathrm{mg}$ per day for 8 weeks after the genotype identification. The vast majority of them were selected from the above study samples, and a few subjects were new diagnostic cases. There were 420 men (58\%) and 304 women $(42 \%)$. The ages ranged from 34 to 76 years, with an average age of $60.18 \pm 12.35$ years. The individuals who had taken lipid-lowering drugs such as statins or fibrates in two weeks were not included in this group. The study protocol was also approved by the Ethics Committee of our First Affiliated Hospital. All patients signed an informed consent form. The individuals with total cholesterol (TC) $>5.17 \mathrm{mmol} / \mathrm{L}$, and/or TG $>1.70 \mathrm{mmol} / \mathrm{L}$ were defined as hyperlipidemic [29-32]. Clinical biochemistry analyses including serum lipid levels were performed before and after 8 weeks of atorvastatin treatment.

\section{Biochemical measurements}

Venous blood sample was obtained from all subjects after at least 12 hours of fasting. The levels of serum TC, TG, HDL-C, and low-density lipoprotein cholesterol (LDL-C) in samples were determined by enzymatic methods with commercially available kits. Serum apolipoprotein (Apo) A1 and ApoB levels were detected by the immunoturbidimetric immunoassay. The normal values of serum TC, TG, HDL-C, LDL-C, ApoA1, ApoB levels and the ApoA1/ApoB ratio in our Clinical Science Experiment Center were 3.10-5.17, 
$0.56-1.70, \quad 1.16-1.42, \quad 2.70-3.10 \mathrm{mmol} / \mathrm{L}, \quad 1.20-1.60$, $0.80-1.05 \mathrm{~g} / \mathrm{L}$ and $1.00-2.50$, respectively [29-32]. Hypertension was diagnosed according to the criteria of the JNC 7 hypertension guidelines [33]. T2D was diagnosed according to the American Diabetes Association (ADA) criteria for DM in 2012 [34]. Normal weight, overweight and obesity were defined as a body mass index $(\mathrm{BMI})<24,24-28$, and $>28 \mathrm{~kg} / \mathrm{m}^{2}$; respectively [35].

\section{SNP selection and genotyping}

The rs4076317, rs7255436, rs1044250 and rs2967605 SNPs were selected on the basis of the following assumptions: (1) Selected SNPs were established by Haploview (Broad Institute of MIT and Harvard, USA, version 4.2); (2) Information of the SNPs was obtained from NCBI dbSNP Build 132 (http://www.Ncbi.nlm.nih.gov/SNP/); (3) SNPs were restricted to minor allele frequency (MAF) $>1 \%$. (4) SNPs might be associated with serum lipid levels and the risk of CAD and IS in recent studies [7, 8, 10, 36-38].

Genomic deoxyribonucleic acid (DNA) was extracted from leucocytes of venous blood using the phenol-chloroform method. Genotyping of the four SNPs was performed by the Snapshot technology platform in the Center for Human Genetics Research, Shanghai Genesky Bio-Tech Co. Ltd.

\section{Statistical analyses}

The statistical software package SPSS 21.0 (SPSS Inc., Chicago, Illinois) was used for the statistical analyses. Quantitative variables were expressed as mean \pm standard deviation (serum TG levels were presented as medians and interquartile ranges because of non-normal distribution). Qualitative variables were expressed as percentages. Allele frequency was determined via direct counting, and the standard goodness-of-fit test was used to test the Hardy-Weinberg equilibrium (HWE). A chi-square analysis was used to evaluate the difference in genotype distribution and sex ratio between the groups. The general characteristics between patients and controls were tested by the Student's unpaired $t$-test. The association of genotypes and serum lipid parameters such as TC, HDL-C, LDL-C, ApoA1, ApoB levels and the ApoA1/ApoB ratio was tested by analysis of covariance (ANCOVA; genotypes and TG using Kruskal-Wallis test). Bonferroni correction was employed for variants associated with serum lipid parameters, and a $P<0.0018(0.05 / 4 \times 7)$ was considered statistical significant. Unconditional logistic regression was used to assess the correlation between genotypes and the risk of CAD and IS after age, gender, BMI, smoking, alcohol consumption, T2D, hypertension and hyperlipidemia were adjusted. The correlation risk was estimated by odds ratio (OR) and $95 \%$ confidence interval $(95 \% \mathrm{CI})$. The pattern of pair-wise linkage disequilibrium (LD) between the selected SNPs was measured by $r^{2}$, and haplotype analyses were performed using the SHEsis software [39]. A two-tailed $P$ value less than 0.05 was considered statistically significant for the remaining variables.

\section{Results}

\section{Characteristics of the study populations}

The clinical characteristics of the patients and controls are shown in Table 1. The differences in age, gender, serum LDL-C and ApoB levels, and the percentages of subjects who smoked cigarettes were not significant between controls and patients $(P>0.05)$. As compared with the controls, more CAD/IS patients had T2DM, hypertension and hyperlipidemia; and the CAD/IS patients also had higher BMI, systolic blood pressure, pulse pressure, serum TG levels, the frequency of using lipid-lowering drugs, and lower serum TC, HDL-C, ApoA1 levels, the ApoA1/ApoB ratio and the percentages of subjects who consumed alcohol $(P<0.05)$. There was no difference in diastolic blood pressure levels between controls and IS patients $(P>0.05)$. In comparison with CAD group, the IS patients had lower BMI and higher blood pressure and serum HDL-C levels, and the prevalence of hypertension $(P<0.05)$.

\section{ANGPTL4 SNPs and the risk of CAD and IS}

The genotypic and allelic frequencies of the ANGPTL4 SNPs are presented in Table 2. The genotype distribution was concordant with the HWE in both cases and controls. Among the four SNPs, only the rs2967605 SNP was shown significant differences in genotype frequencies between the controls and patients $(P<0.05)$. The rs2967605T allele carriers had lower risk of CAD (adjusted $\mathrm{OR}=0.68,95 \% \mathrm{CI}=0.47-0.99, P=0.043)$ and IS (adjusted $\mathrm{OR}=0.55,95 \% \mathrm{CI}=0.38-0.80, P=0.020$ ).

\section{ANGPTL4 SNPs and the angiographic severity of CAD}

As shown in Table 2, there were no significant associations between the four SNPs and the angiographic severity of CAD in different genetic models $(P>0.05)$.

\section{Haplotypes and the risk of CAD and IS}

A significant LD was noted among the rs4076317, rs7255436 and rs1044250 SNPs $\left(r^{2}>0.80\right.$, Table 3$)$. The LD of rs2967605 SNP and other genetic variants was weak in this study. Therefore, the rs2967605 SNP was not included in haplotype analysis. Estimated frequencies of haplotypes derived from three SNPs and their associations with CAD and IS are shown in Table 4. No haplotype of the 3 ANGPTL4 SNPs was associated with the risk of CAD and IS. 
Table 1 General characteristics and serum lipid levels between the controls and patients

\begin{tabular}{|c|c|c|c|c|c|c|}
\hline Characteristic & Control & CAD & IS & $P_{1}$ & $P_{2}$ & $P_{3}$ \\
\hline Number & 549 & 568 & 537 & & & \\
\hline Male/female & $384 / 165$ & $419 / 149$ & $389 / 148$ & 0.155 & 0.364 & 0.619 \\
\hline Age, years & $61.87 \pm 11.12$ & $62.23 \pm 10.59$ & $62.80 \pm 12.41$ & 0.589 & 0.196 & 0.408 \\
\hline Body mass index, $\mathrm{kg} / \mathrm{m}^{2}$ & $22.28 \pm 2.82$ & $23.85 \pm 3.37$ & $23.43 \pm 3.52$ & $<0.001$ & $<0.001$ & 0.041 \\
\hline Systolic blood pressure, mmHg & $130.00 \pm 20.60$ & $132.97 \pm 23.16$ & $147.58 \pm 21.96$ & 0.024 & $<0.001$ & $<0.001$ \\
\hline Diastolic blood pressure, $\mathrm{mmHg}$ & $82.38 \pm 13.01$ & $79.05 \pm 14.06$ & $83.71 \pm 12.95$ & $<0.001$ & 0.092 & $<0.001$ \\
\hline Pulse pressure, mmHg & $49.53 \pm 14.92$ & $53.83 \pm 17.59$ & $63.83 \pm 17.96$ & $<0.001$ & $<0.001$ & $<0.001$ \\
\hline Cigarette smoking, n (\%) & $235(42.8)$ & $246(43.3)$ & $224(41.7)$ & 0.865 & 0.716 & 0.592 \\
\hline Alcohol consumption, n (\%) & $245(44.6)$ & $132(23.2)$ & $144(26.8)$ & $<0.001$ & $<0.001$ & 0.170 \\
\hline Total cholesterol, mmol/L & $4.92 \pm 1.11$ & $4.51 \pm 1.23$ & $4.52 \pm 1.14$ & $<0.001$ & $<0.001$ & 0.836 \\
\hline Triglyceride, mmol/L & $1.01(0.64)$ & $1.36(0.94)$ & $1.35(0.93)$ & $<0.001$ & $<0.001$ & 0.467 \\
\hline $\mathrm{HDL}-\mathrm{C}, \mathrm{mmol} / \mathrm{L}$ & $1.90 \pm 0.49$ & $1.14 \pm 0.34$ & $1.23 \pm 0.40$ & $<0.001$ & $<0.001$ & $<0.001$ \\
\hline LDL-C, mmol/L & $2.74 \pm 0.79$ & $2.71 \pm 1.01$ & $2.68 \pm 0.90$ & 0.549 & 0.245 & 0.638 \\
\hline Apolipoprotein (Apo) A1, g/L & $1.40 \pm 0.24$ & $1.04 \pm 0.52$ & $1.02 \pm 0.22$ & $<0.001$ & $<0.001$ & 0.608 \\
\hline ApoB, g/L & $0.90 \pm 0.21$ & $1.11 \pm 0.75$ & $0.89 \pm 0.25$ & 0.313 & 0.502 & 0.302 \\
\hline ApoA1/ApoB & $1.63 \pm 0.47$ & $1.34 \pm 0.46$ & $1.17 \pm 0.61$ & 0.009 & $<0.001$ & 0.117 \\
\hline Type 2 diabetes, n (\%) & $43(7.8)$ & $91(16.0)$ & $81(15.1)$ & $<0.001$ & $<0.001$ & 0.668 \\
\hline Hypertension, n (\%) & $157(28.6)$ & $200(35.2)$ & $285(53.1)$ & 0.018 & $<0.001$ & $<0.001$ \\
\hline Hyperlipidemia, n (\%) & $175(31.9)$ & $220(38.7)$ & $238(44.3)$ & 0.017 & $<0.001$ & 0.100 \\
\hline
\end{tabular}

$C A D$ coronary artery disease, IS ischemic stroke, $H D L-C$ high-density lipoprotein cholesterol, $L D L-C$ low-density lipoprotein cholesterol. The value of triglyceride was presented as median (interquartile range), the difference between CAD/IS patients and controls was determined by the Wilcoxon-Mann-Whitney test. $P_{1}, C^{2}$ v vs. controls; $P_{2}$, IS vs. controls; $P_{3}$, CAD vs. IS

\section{ANGPTL4 SNPs and serum lipid levels in the controls}

Significant association was found between the genotypes of the rs4076317 SNP and the levels of TC and LDL-C in the controls $(P<0.001$; Table 5$)$, the subjects with the CG/CC genotypes in controls had higher TC and LDL-C levels than the subjects with the GG genotype. There were no significant associations between the remaining 3 SNPs and any serum lipid parameters (Fig. 1).

\section{ANGPTL4 rs4076317 SNP and atorvastatin cholesterol- lowering responses}

After 8-week treatment of atorvastatin, the levels of TC, TG, LDL-C, ApoA1 and ApoB were significantly decreased in the total hyperlipidemic patients $(P<$ 0.001 for all; Table 6$)$. There was no significant difference in serum HDL-C levels. Subgroup analyses showed that the levels of HDL-C in CAD and IS patients were increased after atorvastatin treatment $(P<0.05-0.01)$. There was no significant difference in serum ApoA1 levels in IS patients and CG/GG genotype individuals after atorvastatin treatment. We also showed that the ANGPTL4 rs4076317 SNP changed the effects of atorvastatin on serum lipid levels. The subjects with CG/GG genotypes had lower TC and LDL-C levels than the subjects with $\mathrm{CC}$ genotype after atorvastatin treatment. However, the subjects with $\mathrm{CC}$ genotype had lower ApoA1 levels than the subjects with CG/GG genotypes after atorvastatin treatment (Fig. 2).

\section{Discussion}

Several previous GWASes have revealed associations between the ANGPTL4 SNPs and lipid-related phenotypes or diseases in the European descent. Talmud et al. [35] showed significant associations between the rs1044250 (T266M) and lower serum TG and higher HDL-C levels, although this effect was entirely due to the rs116843064 (rare E40K variant). Inconsistently, Staiger et al. [10] found no reliable correlations between the rs4076317 and rs1044250 SNPs and fasting TG in Germany White population. Meanwhile, Kathiresan et al. [8] revealed that the rs2967605 SNP, which is near ANGPTL4 and located $30 \mathrm{kbp}$ downstream from ANGPTL4, was strongly associated with HDL-C. Dumitrescu et al. [40] also reported that the rs2967605 SNP was associated with HDL-C in European Americans, but not in African American, American Indian, and Mexican American/ Hispanic. Bryant et al. [41] were also unable to 
Table 2 Effect of the ANGPTL4 SNPS on the risk of CAD and IS, angiographic severity of CAD

\begin{tabular}{|c|c|c|c|c|c|c|c|c|c|}
\hline Genotype & Control (\% ) & CAD (\%) & IS (\%) & OR $(95 \% \mathrm{CI})_{\mathrm{CAD}}$ & $P_{C A D}$ & OR $(95 \% \mathrm{CI})_{\text {IS }}$ & $P_{\mathrm{IS}}$ & OR $(95 \% \mathrm{Cl})_{\mathrm{AS}}$ & $P_{\text {AS }}$ \\
\hline \multicolumn{10}{|l|}{ rs4076317 } \\
\hline GG & 7.3 & 7.6 & 7.6 & 1.00 & & 1.00 & & 1.00 & \\
\hline CG & 39.7 & 39.4 & 41.0 & $1.01(0.61-1.67)$ & 0.971 & $0.83(0.50-1.40)$ & 0.493 & $1.20(0.58-2.50)$ & 0.621 \\
\hline CC & 53.0 & 53.0 & 51.4 & $0.94(0.56-1.56)$ & 0.797 & $0.89(0.53-1.48)$ & 0.656 & $0.98(0.47-2.04)$ & 0.947 \\
\hline$P$ & & 0.982 & 0.867 & & & & & & \\
\hline$P_{\mathrm{HWE}}$ & 0.925 & 0.882 & 0.755 & & & & & & \\
\hline Any C vs. GG & 92.7 & 92.4 & 92.4 & $0.92(0.56-1.52)$ & 0.893 & $0.83(0.50-1.37)$ & 0.491 & $1.10(0.54-2.22)$ & 0.800 \\
\hline Any G vs. CC & 47.0 & 47.0 & 48.6 & $0.94(0.72-1.21)$ & 0.611 & $0.96(0.74-1.25)$ & 0.778 & $0.81(0.56-1.19)$ & 0.289 \\
\hline \multicolumn{10}{|l|}{ rs7255436 } \\
\hline AA & 1.3 & 1.2 & 0.7 & 1.00 & & 1.00 & & 1.00 & \\
\hline$A C$ & 15.3 & 15.2 & 14.2 & $0.91(0.27-3.08)$ & 0.885 & $1.06(0.28-4.07)$ & 0.932 & $3.68(0.80-17.06)$ & 0.095 \\
\hline CC & 83.4 & 83.6 & 85.1 & $0.81(0.23-2.83)$ & 0.742 & $0.98(0.25-3.89)$ & 0.974 & $4.22(0.85-21.00)$ & 0.078 \\
\hline P & & 0.995 & 0.581 & & & & & & \\
\hline$P_{\mathrm{HWE}}$ & 0.168 & 0.174 & 0.669 & & & & & & \\
\hline Any $C$ vs. AA & 98.7 & 98.8 & 99.3 & $0.86(0.27-2.79)$ & 0.804 & $1.05(0.27-4.03)$ & 0.944 & 3.75 (0.81-17.36) & 0.090 \\
\hline Any A vs. CC & 16.6 & 16.4 & 14.9 & $0.92(0.65-1.29)$ & 0.615 & $0.92(0.65-1.32)$ & 0.659 & $1.00(0.59-1.68)$ & 0.991 \\
\hline \multicolumn{10}{|l|}{ rs1044250 } \\
\hline$\pi$ & 0.2 & 0.3 & 0.2 & 1.00 & & 1.00 & & 1.00 & \\
\hline$C T$ & 4.2 & 6.0 & 6.1 & $0.87(0.06-12.52)$ & 0.921 & $1.34(0.06-29.65)$ & 0.944 & $3.16(0.19-52.71)$ & 0.424 \\
\hline $\mathrm{CC}$ & 95.6 & 93.7 & 93.7 & $1.19(0.08-18.09)$ & 0.900 & $2.21(0.10-51.65)$ & 0.621 & $4.00(0.21-75.39)$ & 0.355 \\
\hline$P$ & & 0.336 & 0.346 & & & & & & \\
\hline$P_{\text {HWE }}$ & 0.170 & 0.077 & 0.556 & & & & & & \\
\hline Any C vs. TT & 99.8 & 99.7 & 99.8 & $0.87(0.06-12.52)$ & 0.921 & $1.38(0.06-30.53)$ & 0.840 & 3.19 (0.19-53.34) & 0.419 \\
\hline Any T vs. CC & 4.4 & 6.3 & 6.3 & $1.35(0.76-2.42)$ & 0.307 & $1.61(0.90-2.90)$ & 0.111 & $1.14(0.50-2.62)$ & 0.750 \\
\hline \multicolumn{10}{|l|}{ rs2967605 } \\
\hline CC & 12.6 & 17.8 & 17.9 & 1.00 & & 1.00 & & 1.00 & \\
\hline $\mathrm{CT}$ & 48.8 & 44.2 & 44.7 & $0.62(0.42-0.91)$ & 0.015 & $0.48(0.32-0.71)$ & $<0.001$ & $0.72(0.43-1.27)$ & 0.279 \\
\hline$\pi$ & 38.6 & 38.0 & 37.4 & $0.78(0.52-1.16)$ & 0.222 & $0.62(0.41-0.93)$ & 0.020 & $1.05(0.60-1.86)$ & 0.856 \\
\hline$P$ & & 0.043 & 0.047 & & & & & & \\
\hline$P_{\mathrm{HWE}}$ & 0.267 & 0.062 & 0.102 & & & & & & \\
\hline Any T vs. CC & 87.4 & 82.2 & 82.1 & $0.68(0.47-0.99)$ & 0.043 & $0.55(0.38-0.80)$ & 0.020 & $0.86(0.52-1.44)$ & 0.570 \\
\hline Any C vs. TT & 61.4 & 62.0 & 62.6 & $0.88(0.68-1.16)$ & 0.380 & $1.05(0.80-1.37)$ & 0.736 & $0.76(0.51-1.14)$ & 0.183 \\
\hline
\end{tabular}

HWE Hardy-Weinberg equilibrium, CAD coronary artery disease, IS ischemic stroke, AS angiographic severity of CAD. Adjusted for age, gender, BMI, smoking status, alcohol consumption, hypertension, hyperlipidemia and T2DM

Table 3 LD $\left(r^{2}\right)$ between the four ANGPTL4 SNPS

\begin{tabular}{llll}
\hline SNP & rs7255436 & rs1044250 & rs2967605 \\
\hline rs4076317 & $0.87(0.86)$ & $0.90(0.91)$ & $0.67(0.63)$ \\
rs7255436 & - & $0.88(0.85)$ & $0.35(0.36)$ \\
rs1044250 & - & - & $0.28(0.32)$
\end{tabular}

LD $\left(r^{2}\right)$ between IS and control was in brackets replicate this association in non-Hispanic Whites, Hispanics, and African Americans. Parihar et al. [42] also could not find the association between the rs2967605 SNP and HDL-C levels in Americans with extreme obesity. In the present study, we detected the association of the four ANGPTL4 SNPs and serum lipid traits, the risk of CAD and IS in a Southern Chinese Han population. The results showed that the subjects with the rs4076317 CG/CC genotypes had higher TC and LDL-C levels than those with GG genotype. In contrast, no association between the rs4076317 SNP, haplotype carriers and 
Table 4 The association between the haplotypes and CAD/IS

\begin{tabular}{|c|c|c|c|c|c|c|c|}
\hline \multirow[t]{2}{*}{ Haplotypes } & \multicolumn{3}{|l|}{ Frequency (\%) } & \multicolumn{2}{|l|}{$C A D$} & \multicolumn{2}{|l|}{ IS } \\
\hline & Cases $(n=582)$ & CAD $(n=534)$ & IS $(n=553)$ & OR (95\% Cl) & P & OR (95\% Cl) & $P$ \\
\hline$C-A-C$ & 6.5 & 5.5 & 4.6 & $0.83(0.59-1.18)$ & 0.309 & $0.69(0.47-1.00)$ & 0.050 \\
\hline $\mathrm{C}-\mathrm{C}-\mathrm{C}$ & 64.1 & 63.9 & 64.1 & $0.99(0.83-1.17)$ & 0.877 & $0.99(0.83-1.18)$ & 0.934 \\
\hline$G-C-C$ & 27.0 & 27.3 & 28.1 & $1.01(0.84-1.22)$ & 0.883 & $1.06(0.88-1.28)$ & 0.563 \\
\hline
\end{tabular}

Loci are arranged in the order rs4076317, rs7255436 and rs1044250. Haplotype with frequency less than $3 \%$ was pooled and not analyzed

the risk of CAD and IS was observed. In addition, we also found that the rs2967605T allele was associated with a decreased risk of CAD and IS, but no association between the rs2967605 SNP and serum lipid traits was detected.

These findings were different from those of previous studies. The reasons for these different findings remain unclear, one of the important possibilities was different genetic background [8, 41-43]. Somewhat differed with the data from the International HapMap project: the rs4076317G, rs7255436A, rs1044250T and $\mathrm{rs} 2967605 \mathrm{C}$ allele frequencies were $83.9 \%, 61.9 \%$, $31.2 \%$ and $78.3 \%$ in European descent; respectively. In the current study, the frequencies of rs4076317G, rs7255436A, rs1044250T and rs2967605C allele frequencies in controls were $27.1 \%, 8.92 \%, 4.37 \%$ and $37.0 \%$, respectively. These results suggest that the ANGPTL4 variation may have a racial/ethnic-specificity.

Additionally, the underlying molecular mechanisms of the ANGPTL4 were deserved our concern. Several recent reports have indicated that different ANGPTL4 isoforms might exert diverse physiological functions in different tissues [44]. The N-terminal and full-length ANGPTL4 in the bloodstream inhibited the activity of blood LPL. The C-terminus of ANGPTL4 in endothelial cells, however, had been suggested to regulate vascular permeability and angiogenesis [45]. To our knowledge, angiogenesis is the predominant form of neovascularization in atherosclerosis. Neovascularization in early atherosclerosis is associated with inflammation and lipid deposition, and intraplaque angiogenesis is a risk factor for plaque vulnerability to lead to plaque destabilization and rupture [46, 47]. Consequently, ANGPTL4 not only regulated TC by inhibiting LPL, but also affected serum lipid levels and arteriosclerosis by other pathways. The impact of ANGPTL4 on lipids was complex and needed to be further investigated.

Several studies have attempted to address the impact of ANGPTL4 on atherosclerosis development. Adachi et al. [48] showed that fasting and postolive oil-loaded TG levels and atherosclerotic lesion size were largely decreased in ApoE(-/-)/ANGPTL4(-/-) mice compared with ApoE(-/-)/ANGPTL4(+/+) mice, and that genetic knockout of ANGPTL4 protected ApoE(-/-) mice against development and progression of atherosclerosis and strongly suppressed the ability of the macrophages to become foam cells in vitro. Bouleti et al. [49] found that the infarct size was significantly decreased and behavior activity was improved in ANGPTL4-treated transient IS model mice, while vascular damage and infarct severity were increased in ANGPTL4-deficient mice. In accordance, their results showed that ANGPTL4 protects not only the global vascular network, but also interendothelial junctions and controls both deleterious inflammatory response and edema, by restricting Src kinase signalling downstream from vascular endothelial growth factor receptor 2 (VEGFR2). Georgiadi et al. [16] reported that ANGPTL4 over-expression reduced lesion area, macrophage content and numbers of monocytes adhering to the endothelium wall. ANGPTL4 was independently and negatively associated with carotid artery sclerosis measured by 3-T magnetic resonance imaging in subjects with metabolic syndrome and low-grade systemic inflammation. ANGPTL4 suppresses foam cell formation to reduce atherosclerosis development. In accordance, several reports have also revealed the impact of ANGPTL4 variations on the development of atherosclerosis [37, 40]. Folsom et al.

Table 5 Association of the ANGPTL4 rs4076317 SNP and serum lipid levels in the controls

\begin{tabular}{lllllllll}
\hline Genotype & $\mathrm{n}$ & $\mathrm{TC}(\mathrm{mmol} / \mathrm{L})$ & $\mathrm{TG}(\mathrm{mmol} / \mathrm{L})$ & $\mathrm{HDL}-\mathrm{C}(\mathrm{mmol} / \mathrm{L})$ & $\mathrm{LDL}-\mathrm{C}(\mathrm{mmol} / \mathrm{L})$ & $\mathrm{ApoA} 1(\mathrm{~g} / \mathrm{L})$ & $\mathrm{ApoB}(\mathrm{g} / \mathrm{L})$ & $\mathrm{ApoA} 1 / \mathrm{ApoB}$ \\
\hline $\mathrm{GG}$ & 40 & $4.32 \pm 1.40$ & $1.21(0.67)$ & $2.11 \pm 0.49$ & $2.34 \pm 0.69$ & $1.44 \pm 0.24$ & $0.92 \pm 0.25$ & $1.68 \pm 0.59$ \\
$\mathrm{CG}+\mathrm{CC}$ & 509 & $4.97 \pm 1.07$ & $1.00(0.65)$ & $1.89 \pm 0.49$ & $2.77 \pm 0.79$ & $1.39 \pm 0.24$ & $0.90 \pm 0.21$ & $1.62 \pm 0.46$ \\
$P$ & & $<0.001$ & 0.024 & 0.008 & $<0.001$ & 0.311 & 0.998 & 0.283 \\
\hline
\end{tabular}

TC total cholesterol, TG triglyceride, $H D L-C$ high-density lipoprotein cholesterol, $L D L-C$ low-density lipoprotein cholesterol, $A p o A 1$ apolipoprotein $\mathrm{A} 1, A p o B$ apolipoprotein $B$. The value of triglyceride was presented as median (interquartile range), and the difference among or between the genotypes was determined by the Kruskal-Wallis test. A value of $P<0.0018$ was regarded statistically significant after the Bonferroni correction 

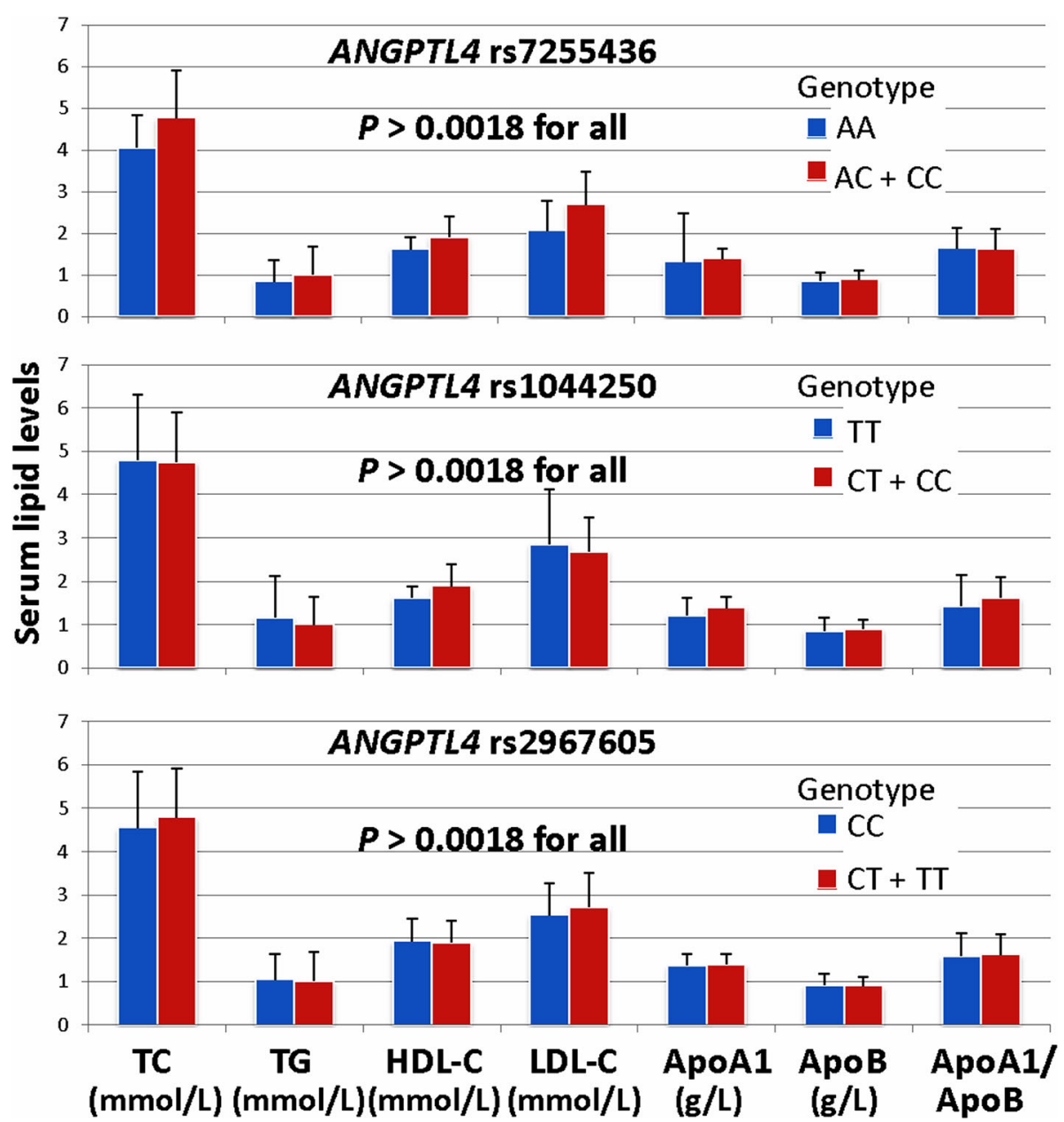

Fig. 1 Association of the ANGPTL4 rs7255436, rs1044250 and rs2967605 SNPs and serum lipid levels in controls. TC total cholesterol, TG triglyceride, HDL-C high-density lipoprotein cholesterol, LDL-C low-density lipoprotein cholesterol, ApoA1 apolipoprotein A1, ApoB apolipoprotein $B$. The value of triglyceride was presented as median (interquartile range), and the difference among or between the genotypes was determined by the Kruskal-Wallis test. $A$ value of $P<0.0018$ was regarded statistically significant after the Bonferroni correction

[9] reported that the ANGPTL4 E40K variant was associated with a decreased risk of CAD. Additionally, He et al. [40] found that the carriers of ANGPTL4 rs4076317GG genotype have lower risk of artery atherosclerotic stroke. Similarly, Muendlein et al. [37] also indicated that the rs $4076317 \mathrm{G}$ allele was a protective effect on future cardiovascular risk, whereas the rs1044250T allele was a risk factor for vascular events. But haplotype defined by the rs1044250T allele provided no additional cardiovascular risk. Inconsistent with previous studies, our research did not discover significant correlations between the rs40 76317, rs1044250 SNPs and the risk of CAD and IS. Significant association was found only for the rs2967605 SNP. We just showed that the rs2967605T allele was associated with a decreased risk of CAD and IS. It suggested that the rs2967605 SNP might be functional genetic variant or, alternatively, was in tight linkage with the causative SNP. However, no significant association between the rs2967605 SNP and angiographic severity of CAD was observed, which suggesting its effects are unlikely to be a major pathway for lower CAD and IS risk, although subtle effects cannot be excluded.

Statins are the most commonly used drugs in patients with dyslipidemia and atherosclerotic diseases. They block the conversion of 3-hydroxy-3-methylglutaryl coenzyme A (HMG-CoA) to mevalonate inhibiting cholesterol synthesis in the liver and are effective at reducing atherosclerosis and cardiovascular risks in clinical practice by lowering LDL-C and total TG levels [50]. However, the pharmacodynamic response to statins varies greatly among patients [51]. Statins reduced the risk of complications and 
Table 6 Effects of the ANGPTL4 rs4076317 SNP on serum lipid levels at baseline and response to atorvastatin therapy in hyperlipidemia

\begin{tabular}{|c|c|c|c|c|c|c|}
\hline Group & $\begin{array}{l}\text { TC } \\
(\mathrm{mmol} / \mathrm{L})\end{array}$ & $\begin{array}{l}\text { TG } \\
(\mathrm{mmol} / \mathrm{L})\end{array}$ & $\begin{array}{l}\mathrm{HDL}-\mathrm{C} \\
(\mathrm{mmol} / \mathrm{L})\end{array}$ & $\begin{array}{l}\text { LDL-C } \\
(\mathrm{mmol} / \mathrm{L})\end{array}$ & $\begin{array}{l}\text { ApoA1 } \\
(\mathrm{g} / \mathrm{L})\end{array}$ & $\begin{array}{l}\text { ApoB } \\
\text { (g/L) }\end{array}$ \\
\hline \multicolumn{7}{|c|}{ Total patient $(n=724)$} \\
\hline Before & $5.33 \pm 1.01$ & $2.12 \pm 1.39$ & $1.44 \pm 0.61$ & $3.17 \pm 0.93$ & $1.19 \pm 0.35$ & $1.04 \pm 0.23$ \\
\hline After & $4.41 \pm 0.46$ & $1.05 \pm 0.32$ & $1.48 \pm 0.49$ & $2.59 \pm 0.46$ & $1.01 \pm 0.23$ & $0.81 \pm 0.15$ \\
\hline$F$ & 22.305 & 20.185 & 1.376 & 15.042 & 11.565 & 22.538 \\
\hline$P$ & 0.000 & 0.000 & 0.169 & 0.000 & 0.000 & 0.000 \\
\hline \multicolumn{7}{|c|}{ Control $(n=253)$} \\
\hline Before & $5.62 \pm 0.71$ & $1.74 \pm 1.51$ & $1.98 \pm 0.54$ & $3.24 \pm 0.72$ & $1.47 \pm 0.25$ & $1.03 \pm 0.19$ \\
\hline After & $4.67 \pm 0.30$ & $0.96 \pm 0.31$ & $1.93 \pm 0.43$ & $2.61 \pm 0.40$ & $1.42 \pm 0.21$ & $0.87 \pm 0.13$ \\
\hline$F$ & 19.604 & 8.049 & 1.152 & 12.166 & 2.436 & 11.055 \\
\hline$P$ & 0.000 & 0.000 & 0.250 & 0.000 & 0.015 & 0.000 \\
\hline \multicolumn{7}{|c|}{$\operatorname{CAD}(n=248)$} \\
\hline Before & $5.14 \pm 1.16$ & $2.29 \pm 1.18$ & $1.13 \pm 0.35$ & $3.08 \pm 1.08$ & $1.06 \pm 0.35$ & $1.05 \pm 0.28$ \\
\hline After & $4.29 \pm 0.48$ & $1.12 \pm 0.31$ & $1.20 \pm 0.31$ & $2.61 \pm 0.52$ & $0.97 \pm 0.25$ & $0.78 \pm 0.16$ \\
\hline$F$ & 10.663 & 15.102 & 2.358 & 6.175 & 3.295 & 13.185 \\
\hline$P$ & 0.000 & 0.000 & 0.019 & 0.000 & 0.001 & 0.000 \\
\hline \multicolumn{7}{|c|}{ IS $(n=223)$} \\
\hline Before & $5.22 \pm 1.02$ & $2.36 \pm 1.37$ & $1.18 \pm 0.49$ & $3.19 \pm 0.96$ & $1.03 \pm 0.21$ & $1.06 \pm 0.22$ \\
\hline After & $4.26 \pm 0.47$ & $1.08 \pm 0.32$ & $1.30 \pm 0.31$ & $2.53 \pm 0.45$ & $1.04 \pm 0.21$ & $0.82 \pm 0.15$ \\
\hline$F$ & 12.765 & 13.587 & 3.091 & 9.296 & 0.503 & 13.460 \\
\hline$P$ & 0.000 & 0.000 & 0.002 & 0.000 & 0.615 & 0.000 \\
\hline \multicolumn{7}{|c|}{ CC genotype $(n=381)$} \\
\hline Before & $5.34 \pm 0.95$ & $2.18 \pm 1.50$ & $1.45 \pm 0.61$ & $3.15 \pm 0.89$ & $1.20 \pm 0.36$ & $1.03 \pm 0.21$ \\
\hline After & $4.56 \pm 0.40$ & $1.07 \pm 0.31$ & $1.52 \pm 0.49$ & $2.70 \pm 0.44$ & $1.04 \pm 0.24$ & $0.82 \pm 0.15$ \\
\hline$F$ & 14.770 & 14.145 & 1.746 & 8.847 & 7.218 & 15.883 \\
\hline$P$ & 0.000 & 0.000 & 0.081 & 0.000 & 0.000 & 0.000 \\
\hline \multicolumn{7}{|c|}{ CG genotype $(n=284)$} \\
\hline Before & $5.29 \pm 1.00$ & $2.04 \pm 1.11$ & $1.42 \pm 0.63$ & $3.18 \pm 0.94$ & $1.19 \pm 0.34$ & $1.06 \pm 0.25$ \\
\hline After & $4.26 \pm 0.45$ & $1.06 \pm 0.33$ & $1.43 \pm 0.49$ & $2.48 \pm 0.44$ & $1.14 \pm 0.29$ & $0.80 \pm 0.17$ \\
\hline$F$ & 15.829 & 14.262 & 0.211 & 11.366 & 1.886 & 14.493 \\
\hline$P$ & 0.000 & 0.000 & 0.833 & 0.000 & 0.060 & 0.000 \\
\hline \multicolumn{7}{|c|}{ GG genotype $(n=59)$} \\
\hline Before & $5.49 \pm 1.18$ & $2.12 \pm 1.78$ & $1.43 \pm 0.48$ & $3.21 \pm 1.06$ & $1.16 \pm 0.28$ & $1.04 \pm 0.26$ \\
\hline After & $4.18 \pm 0.59$ & $0.95 \pm 0.31$ & $1.48 \pm 0.50$ & $2.40 \pm 0.49$ & $1.14 \pm 0.29$ & $0.81 \pm 0.14$ \\
\hline$F$ & 7.627 & 4.974 & 0.554 & 5.327 & 0.381 & 5.983 \\
\hline$P$ & 0.000 & 0.000 & 0.581 & 0.000 & 0.704 & 0.000 \\
\hline
\end{tabular}

TC total cholesterol, TG triglyceride, HDL-C high-density lipoprotein cholesterol, LDL-C low-density lipoprotein cholesterol, $A p o A 1$ apolipoprotein A1, $A p o B$ apolipoprotein B

death from cardiovascular causes by only approximately one third, leaving the remaining two thirds of patients unprotected [52]. Although the mechanisms have not been fully clarified, genetic polymorphisms may play an important role in individual susceptibility to drug response, including the ANGPTL4 genetic variants [53-55]. In the present study, we firstly showed that the ANGPTL4 rs4076317 SNP changed the efficacy of atorvastatin on serum lipid profiles. The subjects with rs4076317CG/GG genotypes had lower TC, LDL-C levels and higher ApoA1 levels than the subjects with $C C$ genotype after atorvastatin treatment. These results suggest that the ANGPTL4 


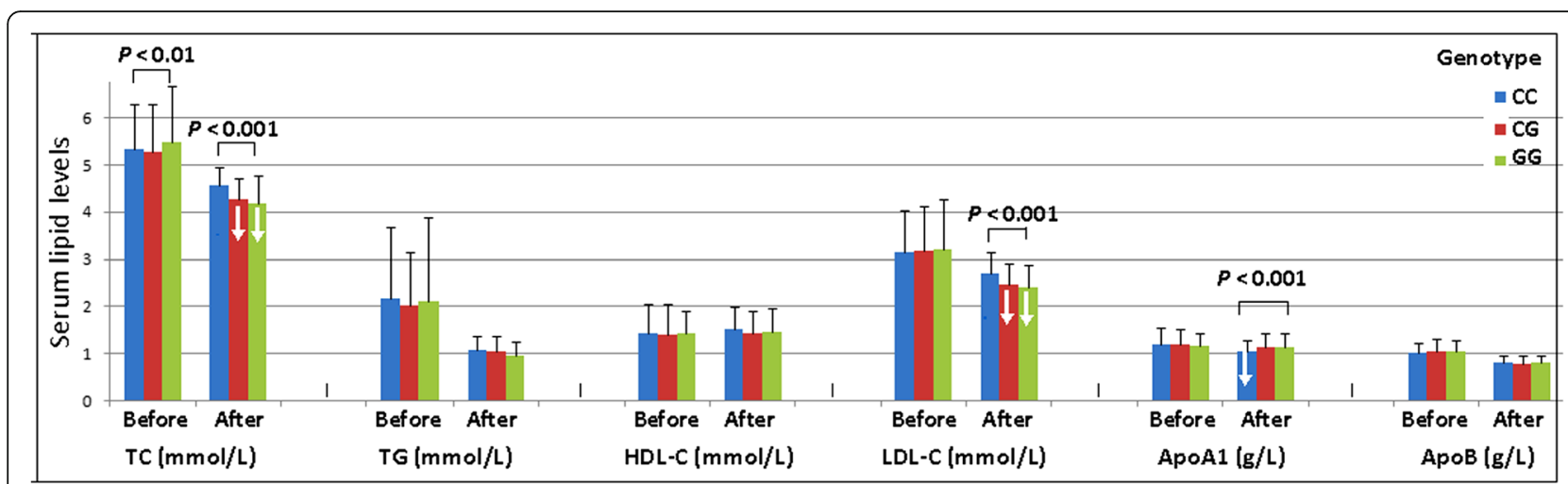

Fig. 2 Effects of the ANGPTL4 rs4076317 SNP on serum lipid levels at baseline and response to atorvastatin therapy in hyperlipidemia. TC total cholesterol, TG triglyceride, HDL-C high-density lipoprotein cholesterol, LDL-C low-density lipoprotein cholesterol, ApoA1 apolipoprotein A1, ApoB apolipoprotein B

rs4076317G allele carriers benefited more from atorvastatin therapy than the ANGPTL4 rs4076317G allele non-carriers in decreasing serum TC and LDL-C levels.

The present study has two potential limitations. First, four SNPs did not cover the whole gene and could not overall elucidate the impact of ANGPTL4 polymorphisms on serum lipid levels and cardiovascular risk. Second, the variant frequency of the rs7255436 and rs1044250 SNPs was relatively low in the Chinese Han population, which the minor allele frequency was $8.92 \%$ and $4.37 \%$ respectively. Significant associations between the two SNPs and serum lipid levels and cardiovascular risk could not be realized, probably to the rarity of the variant implicating limited statistical power. Further larger sample studies are needed.

\section{Conclusions}

The ANGPTL4 rs2967605T allele was associated with a decreased risk of $\mathrm{CAD}$ and IS. The subjects with the rs4076317CG/CC genotypes in controls had higher TC and LDL-C levels than the subjects with the GG genotype. The rs4076317G allele carriers benefited more from atorvastatin therapy than the ANGPTL4 rs4076317G allele non-carriers in decreasing serum TC and LDL-C levels in the Chinese Han population.

\footnotetext{
Abbreviations

ADR1: Adiponectin receptor 1; ANCOVA: Analysis of covariance; ANGPTL4: Angiopoietin-like protein 4 gene; Apo: Apolipoprotein; BMI: Body mass index; CAD: coronary artery disease; Cl: Confidence interval; DNA: Deoxyribonucleic acid; GWAS: genome-wide association study; HDLC: High-density lipoprotein cholesterol; HMG-CoA: 3-hydroxy-3-methylglutaryl coenzyme A; HWE: Hardy-Weinberg equilibrium; IS: ischemic stroke: LD: Linkage disequiblirium; LDL-C: Low-density lipoprotein cholesterol; LPL: Lipoprotein lipase; MAF: Minor allele frequency; OR: Odds ratio; PPAR: Peroxisome proliferator-activated receptor; RCT: Reverse cholesterol transport; SNPs: Single nucleotide polymorphisms; SR-BI I: Scavenger receptor class B type l; T2DM: Type 2 diabetes mellitus; TC: Total cholesterol; TG: Triglyceride; TOAST: Trial of Org 10712 in Acute Stroke Treatment; VEGFR2: Vascular endothelial growth factor receptor 2; VLDLs: Very lowdensity lipoproteins
}

Funding

This study was supported by the Science Foundation of Guangxi Returned Oversea Scholars (No. 0991004) and the National Natural Science Foundation of China (No. 81460169).

\section{Availability of data and materials}

All raw data, materials and histology samples are available with Principal Investigator \& Corresponding author Dr. Rui-Xing Yin.

\section{Authors' contributions}

QY participated in the design, performed the statistical analyses, and drafted the manuscript. R-XY conceived the study, participated in the design, and helped to draft and edit the manuscript. X-LC, FH, YJZ and W-XC collected the data and the samples. All authors read and approved the final manuscript.

Ethics approval and consent to participate

All procedures of the investigation were carried out following the rules of the Declaration of Helsinki of 1975 (http://www.wma.net/en/30publications/ 10policies/b3/), revised in 2008. The study design was approved by the Ethics Committee of the First Affiliated Hospital, Guangxi Medical University (No: Lunshen-2011-KY-Guoji-001; Mar. 7, 2011). Informed consent was obtained from all participants.

\section{Consent for publication}

Not applicable.

\section{Competing interests}

The authors declare that they have no competing interests.

\section{Publisher's Note}

Springer Nature remains neutral with regard to jurisdictional claims in published maps and institutional affiliations.

\section{Author details}

'Department of Cardiology, Institute of Cardiovascular Diseases, the First Affiliated Hospital, Guangxi Medical University, Nanning 530021, Guangxi, People's Republic of China. ${ }^{2}$ Department of Neurology, the First Affiliated Hospital, Guangxi Medical University, Nanning 530021, Guangxi, People's Republic of China. 
Received: 1 May 2018 Accepted: 26 September 2018

Published online: 05 October 2018

\section{References}

1. Smith SC Jr, Grundy SM. 2013 ACC/AHA guideline recommends fixeddose strategies instead of targeted goals to lower blood cholesterol. J Am Coll Cardiol. 2014; 64:601-612.

2. Tsukinoki R, Okamura T, Watanabe M, Kokubo Y, Higashiyama A, Nishimura $\mathrm{K}$, et al. Blood pressure, low-density lipoprotein cholesterol, and incidences of coronary artery disease and ischemic stroke in Japanese: the Suita study. Am J Hypertens. 2014;27:1362-9.

3. Park JH, Hong KS, Lee EJ, Lee J, Kim DE. High levels of apolipoprotein B/AI ratio are associated with intracranial atherosclerotic stenosis. Stroke. 2011:42:3040-6.

4. Teixeira PC, Ducret A, Ferber P, Gaertner H, Hartley O, Pagano S, et al. Definition of human apolipoprotein $\mathrm{A}-\mathrm{I}$ epitopes recognized by autoantibodies present in patients with cardiovascular diseases. J Biol Chem. 2014;289:28249-59.

5. Chapman MJ, Ginsberg HN, Amarenco P, Andreotti F, Boren J, Catapano AL, et al. Triglyceride-rich lipoproteins and high-density lipoprotein cholesterol in patients at high risk of cardiovascular disease: evidence and guidance for management. Eur Heart J. 2011;32:1345-61.

6. Moore KJ, Freeman MW. Scavenger receptors in atherosclerosis: beyond lipid uptake. Arterioscler Thromb Vasc Biol. 2006;26:1702-11.

7. Teslovich TM, Musunuru K, Smith AV, Edmondson AC, Stylianou IM, Koseki $\mathrm{M}$, et al. Biological, clinical and population relevance of 95 loci for blood lipids. Nature. 2010:466:707-13.

8. Kathiresan S, Willer CJ, Peloso GM, Demissie S, Musunuru K, Schadt EE, et al. Common variants at 30 loci contribute to polygenic dyslipidemia. Nat Genet. 2009:41:56-65.

9. Folsom AR, Peacock JM, Demerath E, Boerwinkle E. Variation in ANGPTL4 and risk of coronary heart disease: the Atherosclerosis Risk in Communities Study. Metabolism. 2008;57:1591-6.

10. Staiger H, Machicao F, Werner R, Guirguis A, Weisser M, Stefan N, et al. Genetic variation within the ANGPTL4 gene is not associated with metabolic traits in white subjects at an increased risk for type 2 diabetes mellitus. Metabolism. 2008;57:637-43.

11. Kersten S, Mandard S, Tan NS, Escher P, Metzger D, Chambon P, et al. Characterization of the fasting-induced adipose factor FIAF, a novel peroxisome proliferator-activated receptor target gene. J Biol Chem. 2000:275:28488-93.

12. Yoon JC, Chickering TW, Rosen ED, Dussault B, Qin Y, Soukas A, et al. Peroxisome proliferator-activated receptor gamma target gene encoding a novel angiopoietin-related protein associated with adipose differentiation. Mol Cell Biol. 2000;20:5343-9

13. Lafferty MJ, Bradford KC, Erie DA, Neher SB. Angiopoietin-like protein 4 inhibition of lipoprotein lipase: evidence for reversible complex formation. J Biol Chem. 2013;288:28524-34.

14. Yoshida K, Shimizugawa T, Ono M, Furukawa H. Angiopoietin-like protein 4 is a potent hyperlipidemia-inducing factor in mice and inhibitor of lipoprotein lipase. J Lipid Res. 2002;43:1770-2.

15. Desai U, Lee EC, Chung K, Gao C, Gay J, Key B, et al. Lipid-lowering effects of anti-angiopoietin-like 4 antibody recapitulate the lipid phenotype found in angiopoietin-like 4 knockout mice. Proc Natl Acad Sci USA. 2007;104:11766-71.

16. Georgiadi A, Wang Y, Stienstra R, Tjeerdema N, Janssen A, Stalenhoef A, et al. Overexpression of angiopoietin-like protein 4 protects against atherosclerosis development. Arterioscler Thromb Vasc Biol. 2013;33:1529-37.

17. Johansen CT, Wang J, Lanktree MB, Cao H, Mclntyre AD, Ban MR, et al. Excess of rare variants in genes identified by genome-wide association study of hypertriglyceridemia. Nat Genet. 2010;42:684-7.

18. Li Y, He PP, Zhang DW, Zheng XL, Cayabyab FS, Yin WD, et al. Lipoprotein lipase: from gene to atherosclerosis. Atherosclerosis. 2014;237:597-608.

19. Lichtenstein L, Berbee JF, van Dijk SJ, van Dijk KW, Bensadoun A, Kema IP, et al. ANGPTL4 upregulates cholesterol synthesis in liver via inhibition of LPL- and HL-dependent hepatic cholesterol uptake. Arterioscler Thromb Vasc Biol. 2007:27:2420-7.

20. Koster A, Chao YB, Mosior M, Ford A, Gonzalez-DeWhitt PA, Hale JE, et al. Transgenic angiopoietin-like (ANGPTL)4 overexpression and targeted disruption of ANGPTL4 and ANGPTL3: regulation of triglyceride metabolism. Endocrinology. 2005;146:4943-50

21. Sukonina V, Lookene A, Olivecrona T, Olivecrona G. Angiopoietin-like protein 4 converts lipoprotein lipase to inactive monomers and modulates lipase activity in adipose tissue. Proc Natl Acad Sci USA. 2006;103:17450-5.
22. Dewey FE, Gusarova V, O'Dushlaine C, Gottesman O, Trejos J, Hunt C, et al. Inactivating variants in ANGPTL4 and risk of coronary artery disease. N Engl J Med. 2016;374:1123-33.

23. Stitziel NO. the Myocardial Infarction Genetics and CARDIoGRAM Exome Consortia Investigators. Variants in ANGPTL4 and the risk of coronary artery disease. N Engl J Med. 2016:375:2306.

24. Myocardial Infarction Genetics and CARDIoGRAM Exome Consortia Investigators, Stitziel NO, Stirrups KE, Masca NG, Erdmann J, Ferrario PG, et al. Coding variation in ANGPTL4, LPL, and SVEP1 and the risk of coronary disease. N Engl J Med. 2016;374:1134-44.

25. Gusarova V, O'Dushlaine C, Teslovich TM, Benotti PN, Mirshahi T, Gottesman $O$, et al. Genetic inactivation of ANGPTL4 improves glucose homeostasis and is associated with reduced risk of diabetes. Nat Commun. 2018:9:2252.

26. Chen Q, Reis SE, Kammerer CM, McNamara DM, Holubkov R, Sharaf BL, et al. Association between the severity of angiographic coronary artery disease and paraoxonase gene polymorphisms in the National Heart, Lung, and Blood Institute-sponsored Women's Ischemia Syndrome Evaluation (WISE) study. Am J Hum Genet. 2003;72:13-22.

27. Xu Y, Wang W, Zhang L, Qi LP, Li LY, Chen LF, et al. A polymorphism in the ABCG1 promoter is functionally associated with coronary artery disease in a Chinese Han population. Atherosclerosis. 2011;219:648-54.

28. Adams HP Jr, Bendixen BH, Kappelle LJ, Biller J, Love BB, Gordon DL, et al. Classification of subtype of acute ischemic stroke. Definitions for use in a multicenter clinical trial. TOAST. Trial of Org 10172 in Acute Stroke Treatment. Stroke. 1993;24:35-41.

29. Wu DF, Yin RX, Yan TT, Aung LH, Cao XL, Miao L, et al. The SCARB rs5888 SNP and serum lipid levels in the Guangxi Mulao and Han populations. Int J Med Sci. 2012;9:715-24.

30. Yang $Q$, Yin RX, Zhou YJ, Cao XL, Guo T, Chen WX. Association of polymorphisms in the MAFB gene and the risk of coronary artery disease and ischemic stroke: a case-control study. Lipids Health Dis. 2015;14:79.

31. Yang Q, Yin RX, Cao XL, Wu DF, Chen WX, Zhou YJ. Association of two polymorphisms in the FADS1/FADS2 gene cluster and the risk of coronary artery disease and ischemic stroke. Int J Clin Exp Pathol. 2015:8:7318-31.

32. Huang KK, Yin RX, Zeng XN, Huang P, Lin QZ, Wu J, et al. Association of the rs7395662 SNP in the MADD-FOLH1 and several environmental factors with serum lipid levels in the Mulao and Han populations. Int J Med Sci. 2013;10:1537-46.

33. Phillips B. The JNC 7 hypertension guidelines. JAMA. 2003;290:1314-5.

34. American Diabetes Association. Executive summary: Standards of medical care in diabetes--2012. Diabetes Care. 2012;35(Suppl 1):S4-10.

35. Zhou BF. Effect of body mass index on all-cause mortality and incidence of cardiovascular diseases--report for meta-analysis of prospective studies open optimal cut-off points of body mass index in Chinese adults. Biomed Environ Sci. 2002;15:245-52.

36. Talmud PJ, Smart M, Presswood E, Cooper JA, Nicaud V, Drenos F, et al. ANGPTL4 E40K and T266M: effects on plasma triglyceride and HDL levels, postprandial responses, and CHD risk. Arterioscler Thromb Vasc Biol. 2008:28:2319-25.

37. Muendlein A, Saely CH, Leiherer A, Fraunberger $P$, Kinz E, Rein $P$, et al. Angiopoietin-like protein 4 significantly predicts future cardiovascular events in coronary patients. Atherosclerosis. 2014;237:632-8

38. Legry V, Bokor S, Cottel D, Beghin L, Catasta G, Nagy E, et al. Associations between common genetic polymorphisms in angiopoietin-like proteins 3 and 4 and lipid metabolism and adiposity in European adolescents and adults. J Clin Endocrinol Metab. 2009;94:5070-7.

39. Shi YY, He L. SHEsis, a powerful software platform for analyses of linkage disequilibrium, haplotype construction, and genetic association at polymorphism loci. Cell Res. 2005;15:97-8.

40. He XW, Shen YG, Zhu M, Hu XF, Zheng Z, Liu P, et al. Angiopoietinlike protein 4 serum levels and gene polymorphisms are associated with large artery atherosclerotic stroke. J Neurol Sci. 2016;362:333-8.

41. Bryant EK, Dressen AS, Bunker CH, Hokanson JE, Hamman RF, Kamboh MI, et al. A multiethnic replication study of plasma lipoprotein levels-associated SNPs identified in recent GWAS. PloS One. 2013:8:e63469.

42. Parihar A, Wood GC, Chu X, Jin Q, Argyropoulos G, Still CD, et al. Extension of GWAS results for lipid-related phenotypes to extreme obesity using electronic health record (EHR) data and the Metabochip. Front Genet. 2014;5:222.

43. Dumitrescu L, Carty CL, Taylor K, Schumacher FR, Hindorff LA, Ambite $J \mathrm{~L}$, et al. Genetic determinants of lipid traits in diverse populations from the population architecture using genomics and epidemiology (PAGE) study. PLoS Genet. 2011;7:e1002138. 
44. Grootaert C, Van de Wiele T, Verstraete W, Bracke M, Vanhoecke B. Angiopoietin-like protein 4: health effects, modulating agents and structure-function relationships. Expert Rev Proteomics. 2012;9:181-99.

45. Guo L, Li SY, Ji FY, Zhao YF, Zhong Y, Lv XJ, et al. Role of Angpt/4 in vascular permeability and inflammation. Inflamm Res. 2014;63:13-22.

46. Moreno PR, Purushothaman KR, Zias E, Sanz J, Fuster V. Neovascularization in human atherosclerosis. Curr Mol Med. 2006;6:457-77.

47. Di Stefano R, Felice F, Balbarini A. Angiogenesis as risk factor for plaque vulnerability. Curr Pharm Des. 2009;15:1095-106.

48. Adachi H, Fujiwara Y, Kondo T, Nishikawa T, Ogawa R, Matsumura T, et al. ANGPTL 4 deficiency improves lipid metabolism, suppresses foam cell formation and protects against atherosclerosis. Biochem Biophys Res Commun. 2009;379:806-11.

49. Bouleti C, Mathivet T, Coqueran B, Serfaty JM, Lesage M, Berland E, et al. Protective effects of angiopoietin-like 4 on cerebrovascular and functional damages in ischaemic stroke. Eur Heart J. 2013;34:3657-68.

50. Sever PS, Dahlof B, Poulter NR, Wedel H, Beevers G, Caulfield M, et al. Prevention of coronary and stroke events with atorvastatin in hypertensive patients who have average or lower-than-average cholesterol concentrations, in the Anglo-Scandinavian Cardiac Outcomes Trial-Lipid Lowering Arm (ASCOT-LLA): a multicentre randomised controlled trial. Lancet. 2003;361:1149-58.

51. Bercovich D, Friedlander $Y$, Korem S, Houminer A, Hoffman A, Kleinberg L, et al. The association of common SNPs and haplotypes in the CETP and MDR1 genes with lipids response to fluvastatin in familial hypercholesterolemia. Atherosclerosis. 2006;185:97-107.

52. Libby P. The forgotten majority: Unfinished business in cardiovascular risk reduction. J. Am.Coll. Cardiol. 2005;46:1225-8.

53. Zhang QH, Yin RX, Chen WX, Cao XL, Chen YM. Association between the TIMD4-HAVCR1 variants and serum lipid levels, coronary heart disease and ischemic stroke risk and atorvastatin lipid-lowering efficacy. Biosci Rep. 2018;38:BSR20171058.

54. Su J, Xu H, Yang J, Yu Q, Yang S, Zhang J, et al. ABCB1 C3435T polymorphism and the lipidlowering response in hypercholesterolemic patients on statins: a meta-analysis. Lipids Health Dis. 2015;14:122.

55. Vrablík M, Hubáček JA, Dlouhá D, Lánská V, Rynekrová J, Zlatohlávek L, et al. Impact of variants within seven candidate genes on statin treatment efficacy. Physiol Res. 2012;61:609-17.

Ready to submit your research? Choose BMC and benefit from:

- fast, convenient online submission

- thorough peer review by experienced researchers in your field

- rapid publication on acceptance

- support for research data, including large and complex data types

- gold Open Access which fosters wider collaboration and increased citations

- maximum visibility for your research: over $100 \mathrm{M}$ website views per year

At $\mathrm{BMC}$, research is always in progress.

Learn more biomedcentral.com/submissions 